\title{
Moving SDG5 forward: women's public engagement activities in higher education
}

\author{
Lavinia Hirsu $^{1}$ (D) $\cdot$ Zenaida Quezada-Reyes $^{2} \cdot$ Lamiah Hashemi $^{3}$
}

Published online: 8 September 2020

(C) The Author(s) 2020

\begin{abstract}
Universities play a critical role in the delivery of the Sustainable Development Goals through the third mission, i.e. public engagement activities. However, female academics miss opportunities to be part of this mission because they are caught in many roles that prevent them from getting involved in the SDGs. In light of SDG5, Achieve gender equality and empower all women and girls, we conducted interviews with twenty female academics from Iran and the Philippines to investigate their aspirations, opportunities and experiences with public engagement activities. Our findings show that, while recent gender policies have enabled female academics to develop robust careers, their contributions beyond the walls of the university remain limited because of longstanding patriarchal structures, distrust in women's professional expertise and unchanged systemic constraints. By bringing women's engagement activities forward and supporting them in the delivery of the SDGs, we reframe current debates on women's roles in academia. We argue that HE institutions may enhance their third mission and better achieve the targets of SDGs by valuing women's work and facilitating their engagement activities that may lead to significant societal impact. We conclude our paper with a series of recommendations for policy and practice that support women's journeys in academia.
\end{abstract}

Keywords SDGs · Gender · Women's empowerment · Higher education · Public engagement · Third mission

\section{Introduction}

Who is in charge of the delivery of the Sustainable Development Goals (SDGs)? According to the SDG framework, work on all SDGs should be the result of complex, dynamic and

Lavinia Hirsu

Lavinia.Hirsu@glasgow.ac.uk

1 School of Education, University of Glasgow, Glasgow, UK

2 Philippine Normal University, Manila, Philippines

3 University of Kurdistan, Sanandaj, Iran 
continuous collaborations between multiple academic and non-academic stakeholders (UN 2017a). The SDG framework opens the possibility for innovative partnerships and streams of work that lead to creative solutions to long-lasting global challenges, such as poverty, hunger, health and more pressing issues related to sustainable ecosystems and climate change. Among the multiple stakeholders, higher education (HE) institutions are seen as critical drivers of the SDGs. Through the third mission, i.e. public engagement activities, researchers can use their expertise and extend their knowledge to communities in need. However, to what extent can female academics contribute to the delivery of SDGs when they themselves are caught up in some of the challenges outlined by SDG5 (Achieve gender equality and empower all women and girls)? What roles enable or prevent female academics from having positive societal impact? How can women's work be reconfigured in academia to ensure their full contribution to current global challenges?

To address these questions, this paper explores how female academics position themselves vis-à-vis the third mission of universities. Taking two city-contexts from Iran (Sanandaj) and the Philippines (Manila), we report on findings from twenty interviews with female academics who reflect on their experiences and aspirations. This paper was developed as part of a larger project, Strengthening Urban Engagement of Universities in Africa and Asia (SUEUAA), a collaborative research between academics and public stakeholders. The aim of the project was to explore public engagement activities and possibilities for collaborations between universities and city-level stakeholders to address local challenges such as natural disasters (typhoons, floods, volcanic eruptions, deforestation) and human-induced crises (post-conflict rebuilding and economic sanctions).

We begin this paper by discussing the role of HE in contributing to SDG5 and women's roles in academia. We frame this discussion in the context of well-established debates about traditional roles associated with women's work in universities (e.g. teaching, research, service). Then, we reframe these debates by offering the third mission (TM) of universities as a framework for bringing female academics' professional expertise forward into public engagement activities and the SDGs. Looking at types of engagement, we highlight the entangled nature of female academics' work, exploring women's potential in HE to make significant societal contributions, and the deep seated vulnerabilities and challenges that female academics continue to face. We conclude the paper by highlighting potential interventions that may support the critical role of public engagement for female academics in responding to the SDGs.

\section{The impact of SDG5 in HE and women's roles in academia}

Under the mandate of SDG5, a concerted effort has been directed towards gender mainstreaming, women's empowerment and increased access to HE (UN 2017b). The results have been encouraging as many countries registered growing numbers of female graduates (Hirsu et al. 2018). In part, this trend was encouraged by international, national and institutional policies that established guidelines and strategies for opening access to universities. For instance, in the Philippines, universities draw on a wide range of mandates, from the Beijing Platform for Action and Commission on the Status of Women to the Philippine Plan for Gender-Responsive Development (PPGD 1995-2025), Women's Empowerment, Development and Gender Equality Plan (2013-2016) and the Magna Carta of Women.

In fact, as Cornwall and Rivas (2015) argue, the agenda on gender equality and women's empowerment was embraced so quickly at the policy level to the point that some scholars fear 
that it has lost its "political bite" (p. 396). Gender mainstreaming has become co-opted into neoliberal objectives that flag gender as part of ongoing efforts towards sustainability and development (Alston 2014; Calkin 2015; Wittman 2010). These terms, though, have been wrapped up in the logic of markets, highlighting the importance of gender only insofar as it promotes individual progress and responsibility at the expense of deeper processes of questioning gender-based inequalities or structures of power (Wittman 2010). Although initially SDG5 was to deliver actions for social justice and change, the outcomes of gender mainstreaming have failed to significantly transform women's ways of working in the university.

HE institutions are yet to become environments that fully support the targets of SDG5 (i.e. achieving gender equality and the empowerment of women) because women in academia continue to be bound to specific roles that make their work visible, yet differently valued. Discourses about women's work have presented female academics as "mothers and caregivers" (Ramsay 2007), whose careers suffer from what Frechette (2009) calls "the Mommy Penalty" (p. 6), the career implications when a female academic decides to become a mother (Wolfinger et al. 2008). The discourse of care around female academics' work spills from the private sphere to the professional one because women in HE are often expected to show care and provide pastoral support more than men do (Hughes et al. 2007; Bagilhole 2007). While an ethics of care could potentially change the university environment positively, its association with women's work remains quite problematic (Hughes et al. 2007). In HE, women are assigned to teaching and service roles, such as administrative tasks and committee work, and they find little time for research (Frechette 2009). This distribution of academic activities results in fewer opportunities for promotion and pay equity (Frechette 2009) and fewer leadership roles (Blackmore et al. 2015). It is important to note that these roles manifest themselves differently depending on the country, region, or city where women conduct their work. For this reason, we are careful to evaluate women's roles in this paper in relation to the particular constraints and circumstances of their context.

As we show in the following sections, the above-mentioned roles might explain why female academics at different institutions may be less involved in the delivery of the targets of SDGs, although their professional expertise and capacities are needed for a comprehensive response to global challenges. Recent research has consistently called for a more active involvement of women as "effective risk managers" with creative solutions to support their communities (Enarson et al. 2018). The challenges outlined in the SDGs framework require gender-aware ${ }^{1}$ approaches to represent and address the most vulnerable. For instance, in contexts of crisis and post-disaster response, women are among the most severely affected groups. Disaster experiences are gendered events because such disruptive phenomena are experienced differently by men vs. women (Alston 2014; Bradshaw and Fordham 2015; Enarson et al. 2018). Women register more fatalities in a post-disaster context and do not have the same access as men do to critical information, resources, food and shelter (Sultana 2014; Aipira et al. 2017).

However, to what extent are women in HE prepared and supported to address these issues? What opportunities do women have in developing gender-aware responses to global challenges? By raising these questions, we do not suggest that women will fix gender inequalities

\footnotetext{
${ }^{1}$ We intentionally use the term gender-aware instead of more common alternatives such as gender-sensitive or gender-responsive. We believe that addressing global challenges with the first term assumes that gender dimensions of these challenges have been considered in an integrated way. When trying to find new solutions, we do not respond to gender or are sensitive about gender implications. Instead, we see gender as a significant, integral and ongoing dimension of global challenges.
} 
or develop gendered approaches because of their gendered identities (see Aipira et al. 2017). To the contrary, we wish to explore the potential of female academics making full contributions to the SDG framework based on their professional training and expertise, engaging with a range of global challenges, not only the ones that focus explicitly on gender issues.

To see more progress on the SDGs, researchers suggest that next steps would have to include a firmer "feminist intent" (Alston 2014, p. 293). Women in academia should take more radical stances to approach the SDGs and be part of feminist mobilisations working towards "economic, ecological and gender justice" (Sen 2019). While the authors of this article fully agree with this stance, in this paper we show that the complexity of women's positions in academia makes radical turns difficult to operationalise and, in certain contexts, even undesirable. Instead, we propose an alternative solution: that women's work be reconfigured under the third mission (TM) of universities. The TM enables female academics to bring forward their societal contributions and to position their expertise in a new set of relations that address not only global challenges but also contest and reframe traditional academic roles. Given the scarcity of research on women's engagement activities as part of the TM, with our study, we aim to accomplish two goals: to present women's understanding of the TM and the opportunities they have for engagement in the context of global challenges and to open up a wider conversation on new roles that women in academia might inhabit to fully make use of their professional expertise.

\section{The third mission of universities as a framework for women's work in HE}

The third mission of universities is not a new concept, nor does it have a single definition (Pinheiro et al. 2015; Neary and Osborne 2018). In different contexts, the TM is referred to as applied research, innovation, outreach, knowledge transfer, community engagement or regional development. In the Philippines, the TM is referred to as "extension", i.e. "[t]he extension projects, programs, and activities aim to develop its adopted communities to become empowered, responsible, and sustainable" (CPEO 2016, p. 14). The TM is directly linked to the SDG framework and mapped out onto activities such as: "Adopt-a-Community through Literacy Initiatives for Empowerment (ACTLIFE); Adopt-a-School for Quality Education (ASQUE); and Leadership Capability Building and Disaster Emergency and Relief (DEAR)" (CPEO 2016, p. 15). Regardless of the terminology used, the TM refers to the same core principle: universities should not only teach and deliver excellent research. HE institutions should also fulfil a TM by connecting to local, national and international stakeholders and contributing to societal engagement (Pinheiro et al. 2015). The TM can include activities ranging from university patenting and collaborations with the industry for economic development, spin-offs, technology transfer and knowledge exchange for innovation, public engagement and work with communities (Zomer and Benneworth 2011; Veugelers 2016).

Unlike administration functions that oftentimes refer to activities that help with the management of universities, the TM focusses on engaging academic staff into dynamic networks of knowledge-making and sharing. Academics contribute with solutions to local and global challenges providing evidence-based analyses and helping other stakeholders to take action. Through their professional expertise, academics become key stakeholders in "the systemic nature of the interaction between universities (engaged in knowledge generation and transfer), industry (engaged in the application/ use of knowledge), and government (engaged in the provision of the requisite policy framework for knowledge circulation to thrive)" (Nakwa and 
Zawdie 2016, p. 623). In other words, academics do not only support communities but also contribute more systematically to identifying knowledge-based solutions to complex problems that require multi-stakeholder approaches and a wider set of actions to benefit all those involved (Neary and Osborne 2018).

While TM projects and activities can be geared towards economic development and market-driven responses, social justice and sustainability, both pillars of the SDG framework, can reside at the core of the HE engagement agenda (see Trencher et al. 2014; Appe and Barragán 2017; Neary and Osborne 2018). As universities are suitable institutional bodies for implementing social justice, in practice, they face multiple challenges. As Franco et al. (2019) argue, efforts to gear universities towards sustainable development have not always been systematically supported and valued. Not all universities have developed structures to enable researchers to link their work with public-facing activities. Not all HE institutions attribute the same importance to engagement activities, and this has led to uneven responses to the SDGs and to important differences between universities' social impact across cities, countries and regions. Given its scope, the TM can potentially offer female academics new and exciting opportunities to deploy their professional expertise and contribute to the delivery of the SDGs. However, in light of the above-mentioned challenges that universities face, we wanted to explore how women in HE are able to contribute and navigate these engagement roles. How do they understand the TM alongside other academic roles, as outlined in the previous section of this paper? What are the challenges that women face while using their professional expertise for the delivery of the SDGs?

\section{Methodology}

This research adopted a case study methodology (Flyvbjerg 2011) in line with the SUEUAA project. The SUEUAA collaboration involved academic and non-academic stakeholders in seven cities: Glasgow, Harare, Dar-es-Salaam, Johannesburg, Duhok, Sanandaj and Manila. In each location, we recorded engagement activities where universities and public authorities collaborated to address sustainability challenges. Given the importance of gender inequalities in $\mathrm{HE}$, as signalled by colleagues involved in the project, we focussed this study on women's opportunities in HE. In Iran (Sanandaj) and the Philippines (Manila), female academics seemed to share similar struggles, but also country- and city-specific challenges. As McNae and Vali (2015, p. 288) point out, "The ways in which women deliberately press back against practices of oppression and demonstrate agency in higher education institutions are highly contextual and culturally bound". Our goal was to capture this complex portrait of the academic environment in both cities and to inform future engagement activities and action plans.

The city-level focus was established in light of several factors. The universities involved in the project were located in prominent cities currently confronted with climate- and humaninduced disrupting phenomena: in Manila, floods, earthquakes, typhoons, air and noise pollution, water pollution, increased urban heat, higher numbers of slum areas and persistent gender-based violence (SUEUAA 2017a), and in Sanandaj, water, air and noise pollution, regional political instability, ethnic tensions, severe economic sanctions and urban migration (SUEUAA 2017b). By looking at the range of engagement activities in these cities, we aimed to better understand how academics contribute to the welfare of their immediate communities.

Data for this study was obtained from two sources: (a) initial city profiles that allowed us to understand the wider climate related to the TM of universities and (b) twenty audio-recorded 
interviews with female academics from two universities from Sanandaj and Manila. The interviews were conducted by two of the authors of this article. Using the snowball sampling technique, the authors identified female participants through their professional networks. Given the personal nature of the interview and the potentially sensitive data shared by the interviewees, it was important to build on relationships of trust. Trust was established through pre-existing professional links that the two interviewers had with the interviewees ${ }^{2}$, as well as through the confidentiality clause included in our ethics protocol. Rapport was built during the interviewing process as the interviewers shared similar professional experiences as the ones the interviewees revealed. The semi-structured interviews included questions aimed at capturing experiences of engagement activities within current professional roles and female academics' aspirations. After the data was translated, a thematic approach (Bryman and Bell 2015) was used to analyse the interviews. The identification of the themes and their relevance in the two city-contexts were verified and confirmed by the two authors with local knowledge.

All participants were engaged in teaching and research at their institutions. To present a variety of experiences and professional expertise, we included participants from different disciplinary backgrounds including forestry, behavioural sciences, psychology, public administration, physical education, architecture and construction engineering, chemical engineering, language and literature, agriculture and biosystems. The participants had completed Master's degrees, and, with the exception of four academics, all others had a $\mathrm{PhD}$ degree. Current roles in the university covered leadership and non-leadership positions: from head of department to associate dean, director of linkages and international office, director of sub-units (e.g. Gender Office, Recruitment Office) and faculty member. While the faculty positions represent diverse roles in the university, 12 out of 20 female academics were staff members without leadership roles. Because the third mission of the university is oftentimes linked to research activities, the participants selected for this study were university members actively engaged in research, therefore representing a quite distinct group in the wider population of academic staff.

\section{Types of engagement activities}

"Women have the voice [...] but men are still dominant" (R5PDA $\left.{ }^{3}\right)$

To understand the academic roles that women in HE commit to on a regular basis, we extracted from the interview data a composite profile of our participants. Figure 1 below presents the concurrent roles that female academics in Manila and Sanandaj have at their institutions. The typical roles associated with the main functions of universities emerged: teaching, research, administration and a range of activities that participants identified as the TM. Our interviewees presented teaching and research as the two most valued areas that occupy most of their working hours. Administration tasks supplement these activities and tend to overload the participants, in certain cases even at the expense of research.

For our interviewees, engagement activities fell into four categories:

1 Teacher training and involvement with schools. One of our participants in Manila contributed to the launch of a school for children with cancer in a hospital so the children do

\footnotetext{
${ }^{2}$ In light of this sensitive and personal nature of our paticipants' accounts, the interview dataset is not made publicly available.

${ }^{3}$ To ensure anonymity, all participants' names were replaced by a 4- or 5-digit code.
} 


\title{
TEACHING
}

\section{RESEARCH}

\author{
Teaching courses \\ Training teachers \\ Supervising students \\ Conducting research \\ Involvement in international \\ projects \\ Editor and Journal/Project reviewer

\begin{abstract}
Adviser of studies
Facilitator of events and training

Head/Assistant/Coordinator of

Programmes and Departments

Peer support

Departmental Expert Consultant
\end{abstract} \\ Extension activities \\ Charity and missionary work \\ Environment cleaning projects \\ Consultancy \\ Community coordinator or link
}

\section{ADMINISTRATION}

Fig. 1 Concurrent roles of female academics working in HE (Manila and Sanandaj)

\section{ENGAGEMENT ACTIVITIES}

not miss on their education. Given that our participants were conducting work at educational institutions with teaching roles, it is not surprising that they engaged in teacher training in high schools (Manila) or helped with the development of policies around teacher education (Sanandaj).

2 Charity and/or missionary work. Five of our participants had been involved with charities. Some of them collected donations for local charities. A female academic in Sanandaj worked with two charities, one of which looked after unmarried women or women in abusive relationships. Charity-related activities together with missionary work and bible study in Manila were perceived as "extension", which is how the TM is referred to in HE institutions in the Philippines. Academics appeared to associate the notion of public engagement with the duty of care. As we have indicated in the section on impact of SDG5 in HE and women's roles in academia in this paper, we find this quite problematic and different from the remit of the TM. According to our definitions of the TM, charity work would not be considered an engagement activity because it refers more to a personal choice of community engagement and individual care. To count as a form of TM, charity work would need to be a knowledge-based intervention, a type of engagement that requires expert academic knowledge and procedures, reflected in the university mandate and made available to all academic staff. From our participants' responses, charity work meant providing assistance rather than a knowledge-based intervention, and it featured more with female academics and less with male colleagues.

3 Consultation. One participant mentioned action research, and, as a result, she contributed with data to the development of various policies. Three researchers remarked that they had been asked to help on a consultancy basis, although they believed that being a consultant was not necessarily the strongest form in which they could contribute to the public good. Two participants were consultants in scientific societies that worked with national governments, municipal institutions and subject-specific industries (e.g. engineering companies). 
In the words of our interviewees, the consultation activities were not always empowering:

There were meetings on divorce issues, educational issues, issues relating to female high school and university students, and female administrative workers. [...] the [Provincial Educated Women's Committee] did not have executive powers. The issues discussed where recorded but not implemented; it had guaranteed implementation but was not because it was only set up so that all relevant organizations could say I have such a committee. It was symbolic. [R2PI4]

While consultation would be an important type of engagement leading to societal impact, in the case of our participants, it did not always translate into social change. Such consultations seemed to have a formal role, a type of opinion-check. For many of our participants, the reality of working in universities was quite different: "My engagement in community projects is limited because of the workload" (R9PAS).

4. Environmental responses. Only a few female researchers noted substantial public-facing projects. In Manila, one academic mentioned her involvement in a project that developed a table prototype (La Mesa) to protect pupils in schools during earthquakes. A different project was looking into the production of an earthquake detector for more precise predictions.

The engagement activities listed above may indicate that women in HE are already actively involved in the delivery of the SDG framework. However, caught between long teaching hours, endless administrative tasks and research expectations of international calibre, women researchers wanted to be involved in the lives of their communities but had very little time. At a closer look, time seemed to be only one of the many factors that prevented women from contributing to their communities.

\section{Factors preventing public engagement}

\section{Leadership roles and training}

Efforts towards gender equality and the empowerment of women seem to have reached a "glass roof", as R2PI2 observed in her interview. While SDG5.5 encourages "women's full and effective participation and equal opportunities for leadership at all levels of decision-making in political, economic and public life", these opportunities are quite limited. Constraints on leadership roles emerge from too many on-the-job responsibilities tied to teaching and research and lack of appropriate training and leadership opportunities.

In Manila, four out of ten interviewed female researchers had leadership positions. However, these roles seemed overwhelming because they demanded working extra hours at the expense of family time:

the [university] demands so much time and I am a married person. I have kids, I have husband to think of and thinking of serving the community other than the professional organisation will be too toxic on my part. (R6PDB) 
In the university, researchers are expected to fulfil research roles alongside other tasks, such as administrative duties for which they are not always appropriately trained. For this reason, administration work and even some leadership roles prevented female academics from other types of contributions to the university culture, including the TM: "A director position was given to me but I resigned because it was taking its toll on my health" (R1PRT). In Iran, opportunities for leadership have been even more restrictive:

So partly the reason why women are not in high positions is related to not having the skills or ability and partly it is related to not being given the opportunity to strengthen their skills or even thought of being given a chance. (R2PI4)

According to our participants, in their university contexts, very few women have managed to move to leadership roles. As R2PI7 commented, "women are not trusted", and this embedded assumption in the university culture limits women's career progress. Sohrabizadeh (2016) found similar patterns in her research in Iran where women's participation in crises was constrained even though capacity and interest in such interventions were high.

Leadership is one area where women academics struggle to engage in professional opportunities beyond their primary duties of teaching and research. "The practice of gatekeeping continue[s] to impede women accessing leadership positions" (McNae and Vali 2015, p. 299), and, in doing so, it limits their horizon of action and the possibilities to initiate projects that involve other stakeholders. According to Redmond et al. (2017), women in middle grade positions tend to remain at that level for the rest of their careers without the possibility of moving forward to senior leadership positions. This is a critical area which demonstrates not only the need for continued work on the delivery of SDG 5 but also one of the main reasons why engagement activities are seen as something not central to academic activities. If women academics are not trusted to lead and are overburdened by other tasks, they do not have the necessary support to take their work forward and contribute to the TM.

\section{Individual guilt vs. systemic constraints}

Early in her interview, R9PAS argued that currently " $[\mathrm{t}]$ here are no factors that hinder women from moving into higher positions". This statement was quite surprising because women's accounts of struggle in their academic posts told a different story about barriers in women's professional journeys, despite positive steps towards their inclusion in the university. The majority of our interviewees believed that failures to engage with stakeholders outside the university were personal failures rather than a result of dysfunctional processes in HE.

The discourse of assumed individual guilt was present in the academics' narratives in Manila. As the universities had made extension activities an explicit dimension of work, those academics who did not engage in public-facing projects felt that it had been their fault for limiting their career choices:

I have never thought that I cannot as a woman undertake a managerial post. But one of the problems and reasons for taking a backward step in this regard is my home responsibilities and my responsibilities to my child [...] It was not my colleagues or the university system forcing me to take a back step. I myself made this decision to refuse managerial posts for the moment because of my child. (R2PI2) 
As we moved from one interview to another, "it's my fault" became a recurrent expression that revealed a more complicated process than the stated personal guilt that female researchers were willing to put on their shoulders. Such self-imposed limits fit with neoliberal discourses about individual efficiency and the production of the neoliberal project (Calkin 2015; Morley and Crossouard 2016). In an environment that puts emphasis on individual competences, not taking opportunities to lead and engage in new contexts is perceived as a sign of individual guilt and, more problematically, of choice. When so many constraints related to academic roles and time management restrict the range of actions that women can take in the university, the issue of individual guilt becomes the outcome of two main forces. First, systemic constraints give women and men uneven professional opportunities, and, second, the division of tasks across the profession-home continuum expects women to attend to their family-related roles before they advance their professional goals. In this context, gender inequalities disguised as personal choice are more difficult to address and contest because fault is attributed to isolated individuals rather than to the institutions in which they are embedded:

The greatest challenge that we have in the eastern world is that we operate like 'islands'. As you mentioned, if I cannot as a scientist localise my science in society, you will see many people with lower and incomplete educational level transferring their knowledge to people. So, it is better that I bring my pure scientific knowledge to people, the knowledge that is scientifically proven. (R2PI2)

This statement demonstrates how many Iranian women academics work in their departments: isolated and unsupported in their actions. Researchers in Sanandaj understood the critical role that public engagement plays and the potential consequences if knowledge is not transferred into the public sphere. However, the work needed to transfer knowledge to society was left in women's hands alone, with very little support, training or networking opportunities. The TM of universities is the mechanism through which research and scientific knowledge are applied to wider contexts. In Sanandaj, though, the issue of personal constraints was embedded in a wider framework of institutional limitations: "We have more limitations as women [in Iran] because of social conventions and university frameworks. We do not have written policies but have 'unwritten policies' that limit women" (R2PI1). In a culture where women are not trusted with leadership roles or expected to make key contributions to the university culture, female researchers have to work hard "to demonstrate their value" (Morley and Crossouard 2016, p. 161). This value is weighed against a culture of traditional female roles that prioritise domestic responsibilities over complex professional roles, doubling the sense of inadequacy and guilt of "never doing enough" both at home and at the office. Unfortunately, such "unwritten" codes are hard to capture in official metrics of SDG targets unless they are scrutinised more closely.

\section{Entangled professional and family roles}

According to SDG5.4., across all domains of activities, women should benefit from the recognition and value of "unpaid care and domestic work through the provision of public services, infrastructure and social protection policies and the promotion of shared 


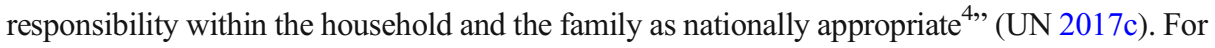
our interviewees and as shown in Fig. 1, the family roles of mother, wife and carer play an overriding role in the achievement of academic goals:

You cannot sacrifice. You can be a good faculty member but if you fail to take care of your family, in the first place, then you are already a big failure. (R2PZ)

The pressure of having growing kids and ensuring they develop the values they need to become better citizens are heavy for a career woman. (R1PRT)

As R1PRT noted, the duty of a caring mother is not only to meet the needs of the child but also a civic duty to form well-rounded citizens. In Manila, fellow researchers are expected to play a major role in the development of their children and need to compromise on their research time (including public engagement) in order to take care of their children and the elderly. Despite longstanding requests from female academics to have a crèche at the university in Manila, this is yet to be achieved. While these values were not contested by our interviewees, what became apparent was the tension and the sense of sacrifice that women had to make between the university and the home, between doing what is required in a professional role and attending to family duties.

In the Iranian context, "home responsibilities are considered a woman's main job" (R2PI3), while the inability to balance private-professional spheres was seen as a private matter with significant repercussions for the professional life. Based on our interviews, the invisbility of women's work moves from the university, where women do not feel safe to take maternity leave and return a week later after giving birth, to the home environment, where men can rest and study while female academics need to do housework, cooking and childcare. Even in cases where women were unmarried and did not have children (especially those who came from outside the city of Sanandaj), they still had to deal with difficult circumstances such as being unable to secure university housing offered to new academic entrants because they were not viewed as family "breadwinners" (R2PI5).

In isolated cases, in Sanandaj, when a supportive partner understood the nature of university work, women could initiate other types of projects:

My marriage has helped me greatly in being prominent in society and having selfconfidence as a woman to stand against any problems and possible discrimination and opposition to my beliefs and defend myself. My partner has had a great role in this. My husband is also an academic on the same level. (R2PI5)

Unfortunately, these cases were isolated instances against an overwhelming majority who struggled to find the right balance between family life and professional work.

Gender inequalities rooted in the distribution of family roles and the division of home labour have been captured in existing literature (Hughes et al. 2007; Ramsay 2007; Blackmore

\footnotetext{
${ }^{4}$ Note the ambiguity of the phrase "as nationally appropriate". While we read this statement as taking steps adapted to national values and available mechanisms for social change, the phrase can also indirectly suggest that softer measures can be taken so as to accommodate national discourses and untroubled expectations of gender roles. While beyond the scope of this paper, this ambiguity is worth exploring further.
} 
et al. 2015). This study adds some important evidence on universities being far from meeting the mandate of SDG5.4. The quality and nature of women's work continue to meet barriers that have become less visible under the apparent successful careers of women-as-teachers and women-as-researchers. As long as the entanglements of home-profession-society are so taxing on women's professional activities, opportunities for addressing global development challenges and making positive societal impact will remain narrow.

\section{The silence of professional expertise}

While female academics in Manila and Sanandaj were familiar with the notion of public engagement, we observed that the TM of universities was not always understood in relation to professional expertise and knowledge-making practices. In other words, female academics engaged with the public yet not in their areas of expertise. While some of our interviewees admitted to have been involved in charity or environmental projects, as in the case of academics in Manila, the range of their disciplinary expertise was not always reflected in those activities. Similarly, in Sanandaj, female academics could see their potential at local, national, regional and international levels; however, not many projects allowed them to engage with communities beyond the university.

In Iran, the silence of women's professional expertise in the delivery of the TM was in part exacerbated by the issue of trust and the culture of inequality between women's contributions vs. men's involvement. As one participant stated, "I wasn't seen as an independent person who could be a leader in undertaking work and be trusted. I have always been on the margins" (R2PI9). While all participants showed interest and excitement in sharing their expertise, in many cases, they felt that their knowledge could not be fully utilised because social and academic expectations placed female researchers into caring roles rather than the role of experts in their fields: "I have never had any such projects and have never been consulted as an expert, but I feel I have the full ability to go forward if I have a problem solving project" (R2PI5).

In Sanandaj, few women researchers had opportunities to be more actively engaged in environmental issues such as waste management and water shortages. One of our participants contributed to charity walks and environmental initiatives such as cleaning the city; yet, these actions were deployed at a small scale, with very little potential for expanded citywide activities. Only a few successful cases of public engagement were shared, including a cultural project where research on local heritage led to the renaming of streets in Sanandaj.

The question of professional expertise emerged in our interviews because female researchers did not always know how to make use of their academic knowledge. For example, R2PI2 collected donations and tried to help families affected by earthquakes financially, but, because she had to attend to her family and meet her work commitments, she could not help the communities in other ways. Her colleague, though, who was a female psychologist, spent 2 months in an improvised tent and offered psychological assistance to the victims of the earthquake.

These challenges and the issue of professional knowledge need to be brought forward as they continue to perpetuate women's marginalisation in academia. In Iran, for instance, projects that involve local municipalities and collaborations with various industry sectors are highly competitive and rely on personal connections. Even when women researchers wanted to apply for a project, they would find out about the call too late because information did not reach them in time: 
The male colleagues chatting and drinking tea together leads to them [men] sharing information [...] It might be little things but in general they are important and have an effect on the motivation to work. You feel your efforts are not worth much. (R2PI4)

Gender inequalities can be easily hidden under the culture of competitiveness, rendering invisible deeper processes of knowledge transfer and circulation. These processes escape generic measurements of gender equality and opportunity unless qualitative in-depth investigations, as the one we propose here (also see Taylor and Mahon 2019), reveal the nature of relationships between academics and their roles within the university. Inconsistent monitoring measures for gender equality (Dhar 2018) and gender quotas (RezaiRashti 2015) would probably leave undetected micro-decisions that affect women's well-being. For instance, in Sanandaj, female academics lost their sports classes because they were told that these sessions had low numbers of participants which did not justify the effort of organising them. Equally problematic is the lack of access to English classes that prevents women researchers from working with international peers who could support them in better positioning their work. When decisions are made to cancel women's classes due to the small number of participants, such decisions are not made just to increase the efficiency of the university, but they are gendered decisions that put women academics at a disadvantage.

\section{Practice and policy implications}

The SDG framework calls for new configurations of work and new alignments of stakeholders in addressing global challenges. In this paper, we offered a different view on women academics' experiences by moving beyond the binary professional vs. domestic roles (Ramsay 2007; Frechette 2009). The TM of universities gives us a new lens into understanding what works and does not work in the professional journeys of female academics. We hope to have shown the potential of the TM to provide a critical space for intervention that women in $\mathrm{HE}$ are currently very interested in being part of. Through the TM, women's academic work can be brought forward more readily, and their professional expertise can be utilised by taking their knowledge from the confines of the university into the public sphere.

At the same time, given the heavy teaching and research workload of women in academia, we advocate for the importance of engagement activities with great caution as this has the potential to become an added burden to the work that women are already doing. We also recommend that the TM should not be flagged as an imperative for all as this would be against the principle of academic freedom and professional relevance of each academic's work (research across all disciplines may have variable direct social impact). Yet, for female academics who want to make an impact based on their expertise, the TM should not be a cost weighed against their other professional duties or, worse, their own personal lives. In this sense, we invite universities to pay particular attention to how the TM can be integrated with research and teaching activities, systematically and comprehensively, with clear policies and structures of support in place and with appropriate recognition of engagement work (Veugelers 2016; Pinheiro et al. 2015).

Based on our interviewees' evaluations and our own assessment, we propose the following action points for policy and practice to support women's journeys in HE: 
- Flexibility of work and more fluid working spaces. These are crucial for women to balance professional and home tasks. Being able to work from home or having access to on-site day care centres, breast feeding stations and diaper changing rooms were pointed out as facilities in dire need.

- Increased access to international professional organisations. External links allow women to learn more about ways of integrating knowledge exchange and impact activities into regular academic activities. These can lead to opportunities for new partnerships and creative knowledge exchange experiences.

- Training women in skills and capacities that enable them to fully engage in the TM. Training should emphasise women's professional expertise and the application of their knowledge to issues relevant to their communities. Lack of such opportunities should not be viewed as individual faults and need to be treated as systemic problems at different levels of university structures. More importantly, female academics should be made aware of all types of engagement activities they might have access to. Involvement with the industry sector, spinoffs and patenting inventions are all part of the TM, but, during our interviews, none was mentioned as a possibility for current or future engagement.

- Parity in professional support. While at the macro-level, women seem to have gained ground in HE, our qualitative analysis shows that micro-arrangements (e.g. sports classes) are not equally offered to men and women. Attention to all levels of support should demonstrate equitable distribution of resources.

- Inequalities among LGBTQI staff should be addressed explicitly and fully. In Manila, professionals with different gender identities have been confronted with issues such as sexual harassment, bullying and gender-based violence. In Iran, such topics are hardly ever brought into conversation. Currently, strategies are being developed to build inclusive environments that condemn all forms of gender-based discrimination and violence, but more efforts need to focus on the implementation of university guidelines and policies.

Across all action plans, men's involvement in supporting female peers and working collaboratively on societal impact needs to be addressed as well. As one of our interviewees noted, "[universities] have to take a risk on women and the men have to work on themselves" (R2PI6) by addressing their own biases and creating more robust collaborations and support structures with female colleagues. Exclusionary practices need to be made visible and rendered unacceptable (Cornwall and Rivas 2015). In patriarchal societies, such as the Iranian context, little change will occur if male academics are not involved in training and policy implementation. In our data, there were few cases where men helped their partners achieve professional goals. Without dedicated programmes for all, gender inequalities will not be fully addressed by policies alone. In the face of global challenges and natural disasters, men should also reflect on their own positionalities, acknowledging their own vulnerabilities and women's contributions (Enarson and Pease 2016).

Public engagement is critical if we want to address current problems and impending global challenges in a holistic way. Women should be at the heart of these responses, not only "involved in relief operation, taking care of the aged and impaired members of the community but in planning for disaster" (R7PDV). No significant progress will be made on any of the SDGs if we exclude women's experiences, understandings and professional expertise. As Bradshaw and Fordham (2015) argue, by not placing women at the heart of social and environmental problems or disasters, we risk a "double disaster" because solutions would only be partial and with devastating long-term consequences at multiple levels. In fact, women do not need to be 
implicated in these issues because they are already involved in reconstruction processes, in response teams, at the site where immediate care is needed. However, a HE journey has prepared them for more, and their impact in society can be expanded through the TM.

Some scholars would argue that a more radical agenda (Alston 2014) could push for more progress on SDG5. Our interviews demonstrate that women's roles are so entangled with social expectations, traditions and cultural practices that a radical turn may not be immediately possible. Our peers in Manila and Sanandaj do not want to give up on their family roles and, simultaneously, want to be able to further their careers. The global challenges we are facing are and will continue to impact us all, and, for an appropriate response, we need all the resources and human power available in HE and beyond. This may be a moment of critical reconfigurations of how research and public engagement can be brought together. Addressing the SDGs in the next decade will require different lenses and innovative ways to respond to social needs. The TM is one such lens that may enable women's work to take full stage in HE. To see this in action, universities need to reaffirm their commitment to implement genderaware policies into practice across all their structures by building on the full professional expertise that all its academic members can bring forward.

Acknowledgements We would like to thank our participants for trusting us with rich accounts of their academic journeys and our two anonymous reviewers for their incredible support in the revision process.

Funding This article draws on data collected for the SUEUAA project (Reference CI170271), funded by the British Academy, the Cities and Infrastructure programme, part of the Global Challenges Research Fund under the UK's Official Development Assistance (ODA) commitment.

Open Access This article is licensed under a Creative Commons Attribution 4.0 International License, which permits use, sharing, adaptation, distribution and reproduction in any medium or format, as long as you give appropriate credit to the original author(s) and the source, provide a link to the Creative Commons licence, and indicate if changes were made. The images or other third party material in this article are included in the article's Creative Commons licence, unless indicated otherwise in a credit line to the material. If material is not included in the article's Creative Commons licence and your intended use is not permitted by statutory regulation or exceeds the permitted use, you will need to obtain permission directly from the copyright holder. To view a copy of this licence, visit http://creativecommons.org/licenses/by/4.0/.

\section{References}

Aipira, C., Kidd, A. \& Morioka, K. (2017). Climate change adaptation in Pacific countries: Fostering resilience through gender equality. In W. Leal Filho (Ed.). Climate Change Adaptation in Pacific Countries, https://doi.org/10.1007/978-3-319-50094-2_13.

Alston, M. (2014). Gender mainstreaming and climate change. Women's Studies International Forum, 47, $287-$ 294.

Appe, S., \& Barragán, D. (2017). Universities, NGOs, and civil society sustainability: Preliminary lessons from Ecuador. Development in Practice, 27(4), 472-486.

Bagilhole, B. (2007). Challenging women in the male academy: Think about draining the swamp. In P. Cotterill, S. Jackson, and G. Letherby (eds.). Challenges and Negotiations for Women in Higher Education (pp. 2132).

Blackmore, J., Sánchez-Moreno, M., \& Sawers, N. (2015). Globalised re/gendering of the academy and leadership. Gender and Education, 27(3), iii-vii. https://doi.org/10.1080/09540253.2015.1028738.

Bradshaw, S., \& Fordham, M. (2015). Double disaster: Disaster through a gender lens. Hazards, risks, and disasters in society. pp. 233-251. https://doi.org/10.1016/B978-0-12-396451-9.00014-7.

Bryman, A., \& Bell, E. (2015). Business research methods. New York, NY: Oxford University Press.

Calkin, S. (2015). Feminism, interrupted? Gender and development in the era of 'smart economics'. Progress in Development Studies, 15(4), 295-307. 
Cornwall, A., \& Rivas, A.-M. (2015). From 'gender equality and 'women's empowerment' to global justice: Reclaiming a transformative agenda for gender and development. Third World Quarterly, 36(2), 396-415.

CPEO (Community Partnership and Extension Office). (2016). Philippine Normal University Extension manual. Philippine University Press. ISBN: 978-971-568-042-4.

Dhar, S. (2018). Gender and sustainable development goals (SDGs). Indian Journal of Gender Studies, 25(1), 47-78.

Enarson, E., Fothergill, A., \& Peek, L. (2018). Gender and disaster: Foundations and new directions for research and practice. In H. Rodríguez, W. Donner, \& J. Trainor (Eds.), Handbook of disaster research, Handbooks of sociology and social research (pp. 205-223). Cham: Springer.

Enarson, E., \& Pease, B. (2016). Men, masculinities and disaster. New York \& London: Routledge.

Frechette, J. (2009). Women, leadership, and equality in academe: Moving beyond double binds. Forum on Public Policy, 2, 1-26.

Flyvbjerg, B. (2011). Case study. In N. Denzin \& Y. Lincoln (Eds.), The Sage handbook of qualitative research (4th ed., pp. 301-316). Thousand Oaks, CA: Sage.

Franco, I., Saito, O., Vaughter, P., Whereat, J., Kanie, N., \& Takemoto, K. (2019). Higher education for sustainable development: Actioning the global goals in policy, curriculum and practice. Sustainability Science, 14, 1621-1642.

Hirsu, L., Reyes, Z., Hashemi, L., Ketuly, K. A. \& Mohammad, S.A. (2018). The role of gender mainstreaming in city-level interventions and leadership: Examples from Manila, Duhok and Sanandaj. SUEUAA Thematic Paper Series, TPS 103/18. Working Paper. CR\&DALL, Glasgow. ISSN 2517-5548 (online) ISSN 2517$553 \mathrm{X}$ (print).

Hughes, C., Clouder, L., Pritchard, J. Pukis, J. \& Barnes, V. (2007). Caring monsters? A critical exploration of contradictions and ambiguities. In P. Cotterill, S. Jackson, and G. Letherby (Eds.). Challenges and Negotiations for Women in Higher Education, (pp. 131-147). Springer.

McNae, R., \& Vali, K. (2015). Diverse experiences of women leading in higher education: Locating networks and agency for leadership within a university context in Papua New Guinea. Gender and Education, 27(3), 288-303.

Morley, L., \& Crossouard, B. (2016). Gender in the neoliberalised global academy: The affective economy of women and leadership in South Asia. British Journal of Sociology of Education, 37(1), 149-168.

Nakwa, K., \& Zawdie, G. (2016). The 'third mission' and 'triple helix mission' of universities as evolutionary processes in the development of the network of knowledge production: Reflections on SME experiences in Thailand. Science and Public Policy, 43(5), 622-629.

Neary, J., \& Osborne, M. (2018). University engagement in achieving sustainable development goals: A synthesis of case studies from the SUEUAA study. Australian Journal of Adult Learning, 58(3).

Pinheiro, R., Langa, P.V. \& Pausits, A. (2015). One and two equals three? The third mission of higher education institutions. European Journal of Higher Education, 5(3), 233-249. https://doi.org/10.1080 /21568235.2015.1044552.

Ramsay. K. (2007). Women: Mothers and others. Discourses of women and motherhood in three academic departments. In P. Cotterill, S. Jackson, and G. Letherby (Eds.). Challenges and Negotiations for Women in Higher Education (pp. 33-52). Springer.

Redmond, P., Gutke, H., Galligan, L., Howard, A., \& Newman, T. (2017). Becoming a female leader in higher education: Investigations from a regional university. Gender and Education, 29(3), 332-351.

Rezai-Rashti, G. M. (2015). The politics of gender segregation and women's access to higher education in the Islamic Republic of Iran: The interplay of repression and resistance. Gender and Education, 27(5), 469-486.

Sen, G. (2019). Gender equality and women's empowerment: Feminist mobilization for the SDGs. Global Policy, 10(1), 28-38.

Sohrabizadeh, S. (2016). The neglect of women's capacities in disaster management systems in Iran: A qualitative study. Indian Journal of Gender Studies, 23(3), 467-480.

SUEUAA (2017a). City Profile: Manila. http://sueuaa.org/cities/manila.

SUEUAA (2017b). City Profile: Sanandaj. http://sueuaa.org/cities/sanandaj.

Sultana, F. (2014). Gendering climate change: Geographical insights. The Professional Geographer, 66(3), 372381. https://doi.org/10.1080/00330124.2013.821730.

Taylor, S.R. \& Mahon (R.). (2019). Gender equality from the MDGs to the SDGs: The struggle continues. In S. Dalby, S. Horton, R. Mahon \& D. Thomaz (Eds.), Achieving the sustainable development goals: Global governance challenges. (pp. 54-70). London and New York: Routledge.

Trencher, G., Yarime, M., McCormick, K., Doll, C., \& Kraines, S. (2014). Beyond the third mission: Exploring the emerging university function of co-creation for sustainability. Science and Public Policy, 41(2), 151179.

UN. (2017a). Transforming our world: the 2030 Agenda for Sustainable Development. https://sustainabledevelopment.un.org/post2015/transformingourworld. 
UN. (2017b). Sustainable Development Goal 5: Achieve gender equality and empower all women and girls. https://sustainabledevelopment.un.org/sdg5.

UN. (2017c). Sustainable Development Goal 4: Ensure inclusive and equitable quality education and promote lifelong learning opportunities for all. https://sustainabledevelopment.un.org/sdg4.

Veugelers, R. (2016). The embodiment of knowledge: Universities as engines of growth. Oxford Review of Economic Policy, 32(4), 615-631.

Wittman, A. (2010). Looking local, finding global: Paradoxes of gender mainstreaming in the Scottish executive. Review of International Studies, 36, 51-76.

Wolfinger, N. H., Mason, M. A., \& Goulden, M. (2008). Problems in the pipeline: Gender, marriage, and fertility in the ivory tower. The Journal of Higher Education, 79(4), 388-405. https://doi.org/10.1080 /00221546.2008.11772108.

Zomer, A., \& Benneworth, P. (2011). The rise of the university's third mission. In J. Enders, H. de Boer, \& D. Westerheijden (Eds.), Reform of Higher Education in Europe (pp. 81-101). Sense Publishers.

Publisher's note Springer Nature remains neutral with regard to jurisdictional claims in published maps and institutional affiliations. 